\title{
Dispositivo de confissão e produção de subjetividades docentes
}

\section{Confession devices and production of teaching subjectivities}

\author{
Edileide Patrícia Câmara Lima ${ }^{1}$ \\ Nilsa Brito Ribeiro ${ }^{2}$
}

\begin{abstract}
Resumo: É no domínio de reflexões teóricas acerca das práticas de si que os estudos foucaultianos têm interrogado sobre o modo como, nas sociedades modernas, os sujeitos produzem experiências de si a partir de tecnologias de objetivação e subjetivação, tendo a confissão como um importante dispositivo que, não estando mais restrito à institucionalização eclesiástica, é mobilizado por diferentes aparatos institucionais produtores de subjetividades. Dessa perspectiva teórica, este trabalho tem por objetivo analisar, em escritas de professores da escola básica, como a confissão produz representações e subjetivações de professores no domínio de um programa nacional de formação docente. O corpus é constituído de relatos escritos durante uma formação realizada pelo Pacto Nacional Pela Alfabetização na Idade Certa (PNAIC), no período de 2014 a 2017, em Marabá, PA. Os discursos que circulam nos relatórios escritos, compreendidos como "práticas de si", traduzem-se em dispositivos de confissões por meio dos quais os professores se subjetivam e são subjetivados como profissionais polivalentes, a partir de uma ordem política totalizadora e individualizante, ao mesmo tempo.
\end{abstract}

Palavras-chave: Discurso. Formação. Práticas de si. Confissão.

Abstract: Foucauldian studies have questioned how subjects produce experiences of themselves based on objectification and subjectification technologies in modern societies, based on the domain of theoretical reflections on technologies of the self. Such studies have the 'confession' as an important device that is mobilized by different institutional apparatus that produce subjectivities and are no longer restricted to ecclesiastical institutionalization. This work aims to analyze in the writings of teachers of the basic school how confession produces representations and subjectivations of teachers in the domain of a national teacher training program during this processes. The corpus consists of reports written at a training carried out by the Pacto Nacional Pela Alfabetização na Idade Certa - PNAIC (National Pact for Literacy at the Right Age) from 2014 to 2017, in Marabá, state of Pará. The speeches that circulate in the written reports and understood as "technologies of the self", are translated into confession devices through which teachers, at the same time, subject themselves and are subjectivated as multipurpose professionals, from a totalizing and individualizing political order.

Keywords: Discourse. Training. Technologies of the self. Confession.

\footnotetext{
${ }^{1}$ Universidade Federal do Sul e Sudeste do Pará, Programa de Pós-Graduação em Letras, bolsista CAPES; Secretaria Municipal de Educação de Marabá, Marabá, PA, Brasil. Endereço eletrônico: edileidepc@ hotmail.com. ${ }^{2}$ Universidade Federal do Sul e Sudeste do Pará, Instituto de Linguística, Letras e Artes, Programa de PósGraduação em Letras, Marabá, PA, Brasil. Endereço eletrônico: nilsa@unifesspa.edu.br. Processo $n^{\circ}$ 408069/2016-3 do CNPq.
} 


\section{Introdução}

A questão da relação constitutiva entre o sujeito e os jogos de verdade de cada momento histórico sempre esteve no centro das investigações de Foucault, seja verificando, nos discursos científicos, de que modo o sujeito vai se reconhecendo como sujeito de linguagem, sujeito vivo ou trabalhador, como mostram seus estudos em As palavras e as coisas (FOUCAULT, 2000 [1966]), seja examinando práticas coercitivas e divisoras nas instituições (nos asilos, manicômios, escolas etc.), ou investigando as práticas de si, em que o sujeito se subjetiva e é subjetivado por diferentes dispositivos. Nesta terceira fase de estudos acerca do modo como o sujeito entra em jogos de verdade, Foucault (2006b [1984], p. 265) considera as práticas de si como "um fenômeno bastante importante em nossas sociedades desde a era greco-romana, embora não tenha sido muito estudado". Para o autor, essas práticas tiveram na Antiguidade uma importância e uma autonomia muito maiores do que quando passaram a ser realizadas pelas instituições religiosas, pedagógicas, médicas e outras. Se, nas sociedades antigas, o cuidado de si tinha um sentido de autoformação, um exercício de si sobre si mesmo num sentido ético, nas sociedades posteriores, sobretudo com o cristianismo, essa temática vai se desequilibrar e afastar-se da ética presente na Antiguidade greco-romana.

Entendemos, a partir de Foucault (2006b), que as práticas de constituição de si não são inventadas pelos sujeitos que entram em certos jogos de verdade, mas, resultantes de esquemas que os próprios sujeitos encontram em sua cultura e que lhe são sugeridos ou impostos de alguma maneira. A partir dessa perspectiva teórica, temos como objetivo analisar em escritas de professores da escola básica, durante processos de formação, como a confissão produz representações e subjetivações de professores no domínio de um programa nacional de formação docente. Tomamos como materialidade de análises relatos de experiências pedagógicas escritos por professores da educação básica, em um contexto de formação continuada, no âmbito do Programa Nacional de Alfabetização na Idade Certa (PNAIC), realizado no período de 2014 e 2017, em Marabá, PA.

Nosso foco principal é o modo como o professor é subjetivado e se subjetiva no interior desse programa, por meio de dispositivos de confissão que são relatos de experiências adotados como um aparato pedagógico por meio do qual o professor é orientado a relatar de maneira minuciosa suas práticas pedagógicas. Os relatos dos professores possibilitam ao Programa o acompanhamento e avaliação do desempenho do professor durante o percurso de formação. Assim, interessa-nos apreender como essa política pública de formação de professores é alimentada por saberes que os próprios professores produzem de si em seus relatos, mas a partir de discursos que a própria política produz acerca da docência. 


\section{Da "escrita de si”" como autoformação na antiguidade às tecnologias do eu modernas}

Investigando a "escrita de si" na Grécia e Roma antigas, Foucault (2006a [1983]) observa que esta prática sugere uma vida de autoria de si mesmo entre gregos e romanos, no sentido de uma ética intelectual de desprendimento de si próprio como forma de autoformação permanente e de relação com os outros, levando em consideração que as práticas de si dos gregos e romanos não se voltavam apenas para o cuidado de si mesmo, mas, sugeriam, também, uma relação complexa com os outros. Ou seja, ao escrever sobre as experiências vivenciadas durante o dia, o sujeito estaria se protegendo dos pensamentos impuros, pois sentiria vergonha de tê-los conhecido. Dessa forma, a escrita substituiria o olhar dos companheiros, forçaria o corpo à submissão e frustraria as armadilhas do inimigo (FOUCAULT, 2006a).

Em suas investigações sobre o que nomeou de "escrita de si" dos greco-romanos, Foucault (2006a) classifica essa prática em dois tipos: os hupomnêmata e a correspondência. Os hupomnêmata, segundo o autor, eram livros de contabilidade, registros públicos, cadernetas individuais em que os sujeitos faziam suas anotações, citavam fragmentos de obras, registravam exemplos e ações que foram testemunhadas ou narrativas que foram lidas, reflexões ou pensamentos ouvidos ou que vieram à mente. Esse tipo de escrita constituía uma memória material das coisas lidas, ouvidas ou pensadas; um tesouro acumulado para releituras e meditações posteriores (FOUCAULT, 2006a). A correspondência, por sua vez, era uma espécie de carta que, endereçada ao outro, produziria como efeito a possibilidade de a escrita agir "por meio do próprio gesto da escrita, sobre aquele que a envia. Assim como, pela leitura e releitura, ela age sobre aquele que a recebe" (FOUCAULT. 2006a, p. 153). A carta teria, assim, a função de aconselhar, exortar, admoestar ou consolar o destinatário, constituindo, ainda, para aquele que escreve uma espécie de treino.

Foucault (2006a) viu nestes dois tipos de escrita um ponto de partida para a sua pesquisa histórica sobre o cuidado de si, sobre os processos pelos quais o sujeito racionaliza suas experiências, realiza "um exercício de si sobre si mesmo através do qual se procura elaborar, se transformar e atingir um modo de ser" (FOUCAULT, 2006b, p. 265). Tomando como ponto de partida para suas investigações as práticas de si exercitadas no mundo greco-romano, Foucault constata que, a partir de então, sobretudo no cristianismo, essas práticas passam a assumir, muito mais, a forma de um código de regras, a partir das quais o sujeito deixa de exercitar com autonomia as práticas de si, uma vez que no cristianismo as determinações do cuidado de si passam a decorrer em função da salvação que impõe obediência. É, portanto, dessa investigação das práticas de si da Antiguidade, enquanto busca de uma ética pessoal, que 
Foucault passa a refletir sobre as técnicas de constituição do sujeito, no mundo moderno, sob a compreensão de que

[...] o sujeito se constitui através das práticas de sujeição ou, de maneira mais autônoma, através de práticas de liberação, de liberdade, como na Antiguidade - a partir, obviamente, de um certo número de regras, de estilos, de convenções que podemos encontrar no meio cultural. (FOUCAULT, 2006c, [1984], p. 291).

Desde o século XVIII, segundo Foucault (2010 [1981]), a nova forma de estrutura política de poder que se vem desenvolvendo de modo contínuo é o Estado que, no contexto de um biopoder, passa a racionalizar os problemas a partir de uma arte de governar ou de uma governamentalidade (FOUCAULT, 2008 [1979]). O biopoder, caracterizado por dispositivos tecnológicos que dispõem de um alcance mais extenso e que tomam por alvo não mais o indivíduo, mas a população, se materializa numa biopolítica, em que os dispositivos se apresentam como uma rede produtiva que passa através de todo corpo social sempre subjetivado de acordo com as necessidades do poder, embora a percepção dos indivíduos seja a de que eles próprios detêm o controle de suas próprias decisões. Lembra Foucault que mesmo nesta fase o objetivo do poder continua o mesmo: controlar a fim de uma maior otimização e docilização dos corpos, só que agora não mais individualmente, mas de forma coletiva, atuando sobre a espécie.

Nessa reflexão, Foucault chama a atenção para o fato de que o Estado é considerado por muitas pessoas como um tipo de poder político que ignora os indivíduos, como se se ocupasse apenas dos interesses da totalidade ou de uma classe ou um grupo dentre os cidadãos. Adverte o autor que, ao contrário do que muitas pessoas pensam, o Estado é uma forma de poder tanto individualizante quanto totalizadora, pois, ao mesmo tempo que atua sobre classes ou grupos sociais, interpela os indivíduos em sua mais ínfima subjetividade, não deixando ninguém de fora de suas interpelações. É nessa forma de governo que se pode falar de uma biopolítica, definida pelo autor como uma prática governamental que atua sobre o conjunto da população de uma forma mais sofisticada. O indivíduo (embora sempre interpelado em suas práticas) já não é mais importante, e, sim, a espécie, de tal modo que a gestão da população passa a ser realizada por meio da reforma dos hábitos de vida, hábitos de identidade e outros.

Desde o século XVIII, essa forma de poder passa a racionalizar os problemas propostos à prática governamental pelos fenômenos próprios a um conjunto de seres vivos constituídos em população como saúde, higiene, natalidade, raças e outros. Por causa disso, o investimento em políticas que, ao mesmo tempo que atuam em defesa da sociedade, exercitam certos 
controles por meio de dispositivos que levam a própria população (idosos, loucos, estudantes, jovens, mulheres, negros, deficientes, professores e outros) a exercer seu autogoverno pelo cuidado de si. Embora os mecanismos de controle ocorram de forma diferente do poder disciplinar, nessa nova fase eles não desaparecem, apenas são redimensionados como forma de cuidado com a população desenvolvida pelo biopoder.

No interior dessa arte de governar, segundo Foucault (1995), temos uma época que se caracteriza pela permanente e sempre renovada questão: “O que somos, hoje?” E é a partir dessa questão que o autor passa a se ocupar teoricamente do modo como os indivíduos, por meio de uma tecnologia política de si, são levados a se reconhecerem como sociedade, como parte de uma nação, de um Estado, de um grupo social.

Dessa perspectiva das técnicas de si é que as escritas dos professores em formação são por nós analisadas enquanto dispositivos por meio dos quais os sujeitos conhecem um certo número de regras de condutas e princípios que funcionam como verdades e prescrições pedagógicas. Ou seja, as escritas analisadas são entendidas como respostas a demandas de formação, por meio das quais os professores são orientados a se confessarem, a narrarem suas experiências para serem avaliados pelo próprio programa de formação.

No próximo item, trataremos mais detidamente da confissão enquanto um dispositivo muito comum nos processos de formação, sobretudo naqueles inaugurados pelas políticas brasileiras de cunho neoliberal.

\section{Técnicas de subjetivação de si: a confissão}

Deleuze (2005) considera a subjetividade como a ideia principal dos estudos foucaultianos, derivada do poder e do saber, embora não dependa deles para existir. Compartilhando da mesma concepção de subjetividade defendida por Foucault, Dreyfus e Rabinow afirmam que: "a luta por uma subjetividade moderna passa por duas formas de sujeição, uma que consiste em individualizar de acordo coma as exigências do poder, outra que consiste em ligar o indivíduo a uma identidade sabida e conhecida" (DREYFUS; RABINOW, 1995, p. 113).

Como abordam Deleuze e Guattari (1996), a subjetividade não implica uma posse, mas uma produção incessante que acontece a partir dos encontros que vivemos com o outro. $\mathrm{Na}$ produção de subjetividade o sujeito mantém uma relação de troca, uma vez que cada um, ao mesmo tempo que acolhe os componentes de subjetivação em circulação, também os emite, fazendo dessas trocas uma construção coletiva viva. Assim, a constituição de subjetividades se 
opera por meio de uma série de instituições, práticas e procedimentos vigentes em cada tempo histórico.

Como já referimos, Foucault aborda em seus estudos o fato de nas sociedades modernas as instituições disporem de técnicas que permitem aos indivíduos efetuarem um certo número de operações sobre os seus corpos, suas almas, seu pensamento e sua conduta. Através de técnicas do eu, voltadas à descoberta e à formulação da verdade a respeito de si próprio, os indivíduos não só obedecem a normas e regras a partir das quais são subjetivados, mas, também, produzem a verdade acerca de si mesmos.

Diferentemente das técnicas de subjetivação produzidas na antiguidade, nas sociedades contemporâneas, as técnicas do eu moderno têm como objetivo construir o eu como unidade de uma vontade de verdade, ou seja, os sujeitos são levados a se produzirem para atenderem a uma vontade de verdade que lhes é dada externamente. É com o propósito de uma governamentalidade que, segundo Foucault (2006e [1988]), o Estado passa a aplicar um conjunto de técnicas políticas capaz de fazer do indivíduo um elemento de peso na relação com as instituições de poder. Por isso, segundo o autor, "são as técnicas, as práticas que dão uma forma concreta a esse novo tipo de relação entre a entidade social e o indivíduo" (FOUCAULT, 2006e, p. 309), justamente por se tratar de práticas que produzem e medeiam a relação do sujeito consigo mesmo, num "enlace entre 'subjetividade' e 'experiência de si mesmo"” (LARROSA, 1994, p. 18), grifo do autor). A partir dessas práticas, o sujeito entra em esquemas que o orientam a observar-se, descrever-se, analisar-se e a se reconhecer como um domínio de saber (FOUCAULT, 2006d), por conta própria ou com a ajuda de outros, mas sempre a partir de técnicas que operam sobre o corpo, a alma, o pensamento, e a conduta, de modo a levar o sujeito à transformação de si para o alcance de algum desejo, algum sonho, algum projeto (FOUCAULT, 2006d).

Investigando a produção e mediação pedagógica da experiência de si, Larrosa (1994) adverte que no domínio da formação educacional é necessário atentar-se para a forma complexa, variável, contingente e muitas vezes contraditória do dispositivo pedagógico, lembrando que,

Um dispositivo pedagógico será, então, qualquer lugar no qual se constitui ou se transforma a experiência de si. Qualquer lugar no qual se aprendem ou se modificam as relações que o sujeito estabelece consigo mesmo. Por exemplo, uma prática pedagógica de educação moral, uma assembléia em um colégio, uma sessão de um grupo de terapia, o que ocorre em um confessionário, em um grupo político, ou em uma comunidade religiosa, sempre que esteja orientado à constituição ou à transformação da maneira pela qual as pessoas 
se descrevem, se narram, se julgam ou se controlam a si mesmas. (LARROSA, 1994, p. 20).

A percepção de Larrosa (1994) é muito importante para o nosso propósito investigativo, uma vez que situamos os processos de práticas de si no domínio da formação pedagógica em que a escrita de experiências pedagógicas em situação de formação docente cumpre importante papel como dispositivos de subjetivação. Nesse domínio, o sujeito se vê diante de universais pedagógicos a partir dos quais vislumbra a necessidade de modificar a sua prática para atender a certas vontades de verdade que têm como intuito formar sujeitos dentro de um padrão considerado como ideal de professor ${ }^{3}$. De acordo com nossas investigações, os cursos de formação se ancoram em verdades homogeneizadoras, de forma que os relatos escritos constituem modos de levar os professores a se confessarem a partir de orientações estabelecidas pelos programas de formação. Nos relatos, o professor confessa sua prática, reconhece suas faltas, expõe seus limites, dando, assim, testemunho sobre si mesmo, fornecendo as bases para que o outro o avalie e reconduza suas práticas a partir de modelos estabelecidos, sem que a experiência dos sujeitos em formação entre no cálculo dessa nova racionalidade. Trata-se, portanto, de uma tecnologia de poder pastoral que não mais diz respeito à institucionalização eclesiástica, cuja força diminuiu desde o século XVIII, mas a uma nova forma de organização de poder, ao mesmo tempo totalizadora e individualizante. (FOUCAULT, 1995).

É sob a perspectiva desse novo poder pastoral que as políticas de educação, saúde, segurança e outras asseguram o poder do Estado sobre a população. Cada campo do saber, na medida em que elabora suas formas de subjetividade do outro, interpela o sujeito de forma global e individual, a partir de jogos de verdades que constituem o arquivo de um dado momento histórico.

Adverte Larrosa (1994) que o sujeito construído como objeto teórico e prático de um dado campo do saber, como a pedagogia, por exemplo, caracterizado por certas formas de relação consigo mesmo, não é uma evidência “intemporal” e "acontextual” (LARROSA, 1994, p. 5). E só pode ser analisado, considerando discursos e práticas no interior das quais ele se constitui. Nas palavras do autor:

Antes, entretanto, de mostrar com certo detalhe como se define e se fabrica esse sujeito são e maduro definido normativamente em termos de

\footnotetext{
${ }^{3}$ Gomes (2019), analisando representações do professor em propagandas e reportagens do Ministério de Educação (MEC), publicadas na revista Nova Escola, discute como, na "sociedade da capacitação", produzem-se discursos sobre os professores, "a partir de uma lógica voltada para a homogeneização de identidades docentes, tendo sempre em vista a classificação, hierarquização e padronização de um tipo de professor” (GOMES, 2019, p. 25).
} 
autoconsciência e autodeterminação, e no qual temos certa tendência a nos reconhecer, ao menos idealmente, talvez seja bom um certo exercício de desfamiliarização. E uma vez que se trata de nos desfamiliarizarmos de nós mesmos, nada melhor que aplicar, a isso que somos, o olhar assombrado do antropólogo, esse olhar etnológico, educado para ver, inclusive na idéia que ele tem de si mesmo, as curiosas e surpreendentes convenções de uma tribo particular. (LARROSA, 1994, p. 5-6)

A discussão do autor traz à reflexão a ideia de que o sujeito é histórico, contingente, ainda que nos pareça profundamente familiar ou evidente falarmos de nós mesmos. Por isso, o convite do autor ao contínuo estranhamento e desfamiliarização do sujeito na relação consigo mesmo quando se insere em práticas de si, posto que os jogos de verdade em dadas condições históricas produzem um efeito determinante sobre aquilo que vemos e sabemos sobre nós.

Situando nossos estudos nessa abordagem sobre subjetividades docentes, entendemos que as escritas produzidas pelo professor no interior do PNAIC funcionam como jogos de produção de verdades por meio dos quais o professor é convocado a se narrar, a confessar as suas práticas dentro de uma arte de governar. Nesse sentido, a escrita é tomada como objeto de regulação de subjetividades docentes, ao mesmo tempo que o saber produzido pelo professor sobre si mesmo otimiza as ações do Estado em relação à política de formação. Nas análises a seguir, destacamos a maneira pela qual os relatos de professores funcionam como um dispositivo de confissão a partir dos quais ele se narra, se avalia, expõe seus limites e sonhos. Isso sempre a partir de determinantes históricos orientadores de representações de professor do nosso tempo.

\section{Dispositivos de confissão: análises}

Neste tópico, apresentamos as análises de excertos extraídos de dois relatos de experiências produzidos por duas professoras em formação, como atividade a ser cumprida durante esse processo. Analisamos como a subjetividade do professor se constitui nas narrativas de si, revelando seus saberes sobre o exercício da docência e como os programas de formação atuam na orientação de subjetividades.

\section{Confissão e autorregulação}

Na sequência discursiva 1 (SD1), a seguir, atentamos para gestos de confissão em que o professor se volta para as etapas do trabalho desenvolvido em sala de aula, a partir de uma solicitação dos formadores do Programa. 
(SD1)

Fiz o agrupamento de pré - silábico e silábico com valor e dei uma atividade de escrita. E orientei da seguinte maneira escrevi a primeira dupla de palavras na lousa, uma debaixo da outra. Li em voz alta e pedir para eles fazer a contagens de letras. Então perguntei: nessa palavra todas as letras são iguais? Em cada palavra, que letra transforma uma palavra em outra. Silábico com valor e silábico sem valor, eu dei uma atividade de ilustrar os personagens do conto. E mais dois "ditos normais" trabalhei pintura, recorte e colagem dos personagens do conto. Eu sentei com os dois ditos normais para orientar-los. Eu fiz o agrupamento desse modo porque minha turma é do primeiro ano e tem poucos silábicos com valor. As intervenções feitas nas atividades foram chamar as atenções para as pronuncia das palavras compassadamente e batendo palmas para perceber quantos pedacinhos têm as palavras que eles iriam separar. (Relatório1, $1^{\circ}$ ano, 2017)

Atentando-nos à materialidade linguística da SD1, destacamos as formas verbais $\mathrm{fiz}$, orientei, escrevi, li, perguntei, trabalhei, sentei, pedi, levei, explorei, chamei, usei, confeccionei, todas elas na primeira pessoa, referindo-se ao cumprimento de ações centradas no sujeito da enunciação.

As atividades pedagógicas elencadas pontualmente pela escrevente atestam o cumprimento de um percurso metodológico de ensino da língua centrado em níveis (présilábicos e silábicos): “Fiz o agrupamento de pré - silábico e silábico com valor e dei uma atividade de escrita". A referência da professora ao objeto de ensino, para o qual se volta sua enunciação, se desdobra em um relato minucioso das atividades de escrita desenvolvidas para o alcance da sua proposta. Na sequência, as formas verbais orientei, escrevi, li, perguntei, trabalhei explicitam cada etapa percorrida no processo de ensino, atestando o cumprimento da tarefa encaminhada pelo programa de formação. Tem-se, nesse processo, o que Foucault chama de objetivação de um saber, por meio da qual o sujeito informa ao outro (Estado) aquilo que este (Estado) precisa saber para otimizar sua própria força. Como se pode depreender do relato, não se trata de um saber resultante de um gesto criativo e autônomo do professor, mas da objetivação de um fazer orientado por um dispositivo de confissão que leva tais professores a revelarem aquilo que entendem estar no âmbito das prescrições da proposta de formação.

Essa nossa compreensão se reforça com a sequência por meio da qual a professora justifica o percurso metodológico adotado: "Eu fiz o agrupamento desse modo porque minha turma é do primeiro ano e tem poucos silábicos com valor. A explicativa "porque" produz o efeito de antecipação do outro (formador) em um jogo de forças, ou seja, a professora justifica a metodologia adotada, no que se refere à decisão em trabalhar o ensino a partir de níveis présilábicos e silábicos, precavendo-se em relação a qualquer questionamento ou avaliação negativa que possa advir dos profissionais da formação. Segundo Foucault (2006b, p. 282), esta é a forma como o dispositivo de poder funciona, enquanto um "conjunto de regras ou procedimentos que conduzem a um certo resultado". Dessa forma, a escrita de si, que poderia se constituir como um espaço de reflexão e de emancipação do sujeito professor, acaba 
produzindo o efeito da sujeição, pois o processo de objetivação do trabalho pedagógico desenvolvido parece cumprir mais um ritual estabelecido previamente pelos formadores do que uma decisão própria da professora.

Verificamos em diferentes relatos escritos pelos professores em formação que o dispositivo de confissão é um processo discursivo bastante recorrente (relatórios, relatos de experiências, rotinas de sala de aula, sequências didáticas etc.), principalmente porque os programas de formação continuada desenvolvidos nas últimas três décadas têm adotado com centralidade esse tipo de organização metodológica em que o professor deve confessar ao outro seu saber pedagógico através da objetivação do percurso de atividades pedagógicas desenvolvidas.

Dessa forma, o relato da professora remete à confissão de si, em relação ao trabalho desenvolvido, como uma espécie de "prestação de contas" ao programa. Vale dizer que, à época, o PNAIC disponibilizava para o professor em formação uma plataforma digital (Sispacto) que funcionava como mais um dispositivo de controle do professor. Durante o processo de formação, o professor deveria inserir nessa plataforma relatos das atividades de ensino realizadas, de modo a manter os formadores permanentemente informados. $\mathrm{Na}$ biopolítica, são os próprios sujeitos da formação que, através das práticas de si, oferecem as informações de si mesmos exigidas pelo biopoder. Assim, se por um lado o professor é subjetivado a partir dos dispositivos de formação, por outro ele é objetivado ao prestar contas passo a passo de seu aprendizado, oferecendo ao Estado informações de si mesmo para a avaliação externa. Por exemplo, a professora relata cada ação desenvolvida em cada disciplina e, assim, o programa vai alimentando seus dados estatísticos tão necessários à biopolítica.

Como discute Russi (2015), o importante não é apenas identificar a existência de um dispositivo de confissão, mas identificar como esse dispositivo permite questionar, analisar e tensionar o seu funcionamento. É dessa perspectiva de análise que problematizamos o dispositivo de confissão presente nos cursos de formação, de modo que o espaço da criatividade docente é ocupado por uma racionalidade que exige do professor o cumprimento de um protocolo de atividades sequenciais indiciadoras de uma formação homogênea e universal, descartando nesse gesto a autonomia e a autoria docentes.

No entanto, não obstante o poder pastoral, lembra Foucault (2006b) que é nesse espaço mesmo de práticas de sujeição que podem surgir práticas de liberação, de construção de liberdade, posto que o poder não se encontra afastado da resistência: pelo contrário, eles se implicam. Por isso mesmo, entendemos que a escrita do professor, como espaço de cuidado de si, pode vir a se constituir um espaço de construção de uma ética de si, na medida em que os 
coletivos docentes assumirem sua autonomia na construção de percursos pedagógicos construídos a partir de um projeto coletivo de autoria docente.

\section{A confissão do professor polivalente e eficiente}

De acordo com Farias (1988), a ideia de polivalência no trabalho começou a ser disseminada a partir do contexto socioeconômico de reorganização do capital, estruturada a partir de 1960. É a partir de então que se cria a necessidade de um novo perfil de professor para atender às demandas de formação que o mercado e o novo perfil de aluno passam a exigir desse profissional. $\mathrm{Na}$ década de 1990, com o advento das políticas neoliberais, as propostas e diretrizes educacionais avançam na criação de dispositivos e mecanismos de vigilância e controle sobre a educação. De acordo com o autor, os discursos voltados à necessidade de realização de reformas para implementação de supostas melhorias no âmbito educacional foram e continuam sendo um dos mecanismos mais importantes para a inserção da agenda neoliberal de efetividade e eficiência na educação, tendo a polivalência como o elemento desencadeador desse novo perfil de professor.

No que concerne ao tema da polivalência e eficiência, pretendemos analisar a sequência discursiva 2, como o professor confessa suas práticas, sob o efeito ideológico das políticas neoliberais, na produção de subjetividades de um profissional cuja eficiência reside na capacidade de assunção de múltiplos papeis dentro da escola.

(SD 2)

Quando falamos em educação e educador percebe-se logo que estas duas palavras não podem ser desfarceladas, pois estão interlaçadas porque hoje o educador não só ensina ler e escrever e sim, faz parte de uma vida como um todo, da vida da criança tanto na educação escolar quanto na educação social. Hoje, nós professores temos que ser educador de conhecimentos científicos e de personalidade, pois nossa clientela são de pessoas carentes não só na situação financeira, mas de afeto, amor, carinho, com estes motivos aumenta nossa dificuldade em sala de aula, pois temos que estar buscando encontrar soluções para tentarmos desenvolver e desempenhar um trabalho que esteja dentro das perspectivas educacionais da vida social de cada um (Relatório 7, $3^{\circ}$ ano, 2014)

Esse discurso atualiza a subjetividade de um professor do nosso tempo na seguinte sequência linguística: porque hoje o educador não só ensina ler e escrever...; Hoje, nós professores temos que ser educador de conhecimentos científicos e de personalidade... Ou seja, é possível apreender nas duas ocorrências do advérbio "hoje" um movimento discursivo por meio do qual o professor é convocado a se subjetivar num tempo muito atual, em que são produzidas novas subjetividades docentes demandadas por uma nova ordem política.

É um discurso que, ao situar o professor em um tempo que é nosso, expande a atuação desse profissional para além de um domínio tradicionalmente a ele reservado, sobretudo nas 
séries iniciais da educação básica (não só ensina ler e escrever), e o inscreve em outros domínios (hoje o educador não só ensina ler e escrever e sim, faz parte de uma vida como um todo, da vida da criança tanto na educação escolar quanto na educação social. Hoje, nós professores temos que ser educador de conhecimentos científicos e de personalidade) que ultrapassam a função que em seu imaginário seria ensinar a ler e escrever. As sequências de cada um dos pares: "ler e escrever/parte de uma vida como um todo"; "educação escolar/educação social”; "educador de conhecimentos científicos/ [educador] de personalidade" sugerem, na equivocidade da linguagem, relações de ampliação ou de transbordamentos da função do professor contemporâneo. Se a relação entre as sequências de cada par não é dicotômica, pelo menos, o efeito produzido é de “mal-estar”, de desidentificação. Esse efeito de desfamiliarização parece caracterizar, nesse discurso, a posição que os professores da educação básica são convocados a ocupar nessa nova ordem educacional, assumindo posição de um professor com múltiplos papeis.

Além disso, o deslocamento da atuação do papel do professor é produzido na sequência discursiva, sugerindo que, se por um lado, o professor é subjetivado como aquele que deve responder a múltiplas demandas para além do seu campo de formação, por outro, o sujeito da aprendizagem (aluno), também participante do mundo da formação, é identificado nessa nova ordem neoliberal como um "cliente" que precisa irredutivelmente do trabalho polivalente do professor: "Hoje, nós professores temos que ser educador de conhecimentos científicos e de personalidade, pois nossa clientela são de pessoas carentes não só na situação financeira, mas de afeto, amor, carinho, com estes motivos aumenta nossa dificuldade em sala de aula". A designação de aluno como "cliente" produz o efeito de uma relação de mercado muito presente nas políticas neoliberais inauguradas, no Brasil, sobretudo a partir da década de 1990, em que a lógica de resultados se impõe fortemente aos processos formativos. A necessidade desse "cliente" (aluno) extrapola a situação financeira na medida em que o "produto" da relação é também de ordem afetiva, emocional, produto de que o professor nem sempre dispõe na relação de compra e venda (com estes motivos aumenta nossa dificuldade em sala de aula).

Nesse discurso, o professor se apresenta como a "chave" para a resolução dos problemas sociais que adentram o espaço escolar, embora nem sempre esteja em seu domínio a resolução de tais problemas. Trata-se de um discurso que não tem origem no sujeito do relato, mas no arquivo da educação desse nosso tempo, em que o professor é subjetivado como um sujeito dotado de habilidades e competências supostamente necessárias para a superação de problemas aparentemente pontuais e individuais, quando, na verdade, são problemas estruturais que afetam não apenas a educação, mas a ordem social. Em outras palavras, nesse funcionamento 
discursivo, o professor é compreendido como um prestador de serviço, o aluno como um cliente e o ensino como um produto a ser oferecido ao mercado, no caso, à sociedade. Como bem lembra Fonseca (2018), esses discursos são transformados em

[...] regime de verdade que se caracteriza pela articulação de um certo tipo de discurso sobre uma série de práticas, de modo a constituir-se, de um lado, como um conjunto de saberes inteligíveis e, de outro, referência capaz de legiferar sobre as práticas em termos de verdadeiro ou falso (FONSECA, 2018, p. 120).

Nesse sentido, o discurso do trabalhador polivalente produz a ideologia segundo a qual o professor contemporâneo precisa ter como atributo a facilidade de se adaptar a contextos diversos e ser detentor de várias competências que lhe permitam atuar em diversas áreas de trabalho, aumentando a produtividade aliada à eficiência

\section{Considerações finais}

Neste trabalho, propusemos como objetivo analisar, em relatos escritos por professores da escola básica durante processos de formação pedagógicas, como a confissão produz representações e subjetivações de professores no domínio de uma nova racionalidade de formação docente. As análises de duas sequências discursivas recortadas dos relatórios mostram como o professor é colocado numa relação consigo mesmo por meio de dispositivos de confissão materializados nos relatos escritos e como a subjetividade do professor é delineada de acordo com a representação prescrita pelas políticas de formação. O professor é interpelado por uma biopolítica de formação que, ao mesmo tempo que atua sobre o indivíduo, na medida em que o interpela em práticas de si, atua, também, de forma totalizante, pois as práticas pedagógicas demandadas do professor devem obedecer a roteiros estabelecidos de forma homogênea para todos dos sujeitos da formação.

As análises destacam, ainda, uma representação de professor polivalente, bem aos moldes do que preconizam as políticas de cunho neoliberal, dentre elas, as políticas educacionais que se inserem em um discurso muito alinhado com o discurso mercadológico, em que prevalecem a lógica de resultados, a classificação por méritos e a ênfase em habilidades individuais. Considerando que a relação entre sujeitos e jogos de verdades são relações determinadas por condições históricas, ao se alinhar com o discurso da competência multifuncional, a prática discursiva do professor revela como as verdades produzidas nas esferas de poder investem na fabricação de sujeitos por meio de dispositivos que possibilitam 
a esses sujeitos narrarem-se de acordo com as verdades estabelecidas externamente em uma dada época.

Nessa nova lógica de poder-saber, o professor é instado a se subjetivar conforme as demandas do poder, de modo que as práticas de si não se referem mais a uma prática coercitiva, mas a uma prática de autoformação. Com a implementação de políticas públicas educacionais brasileiras, o professor é colocado diante de uma variedade de regras, condutas, princípios e mecanismo norteadores do seu fazer, entendidas como formação continuada, atualização profissional, formação em trabalho e qualificação docente. Mas, no bojo dessas políticas, "desenha-se" um ideal de professor a ser seguido de forma padronizada, uma vez que os dispositivos, técnicas e práticas de si conduzem os sujeitos a uma homogeneização de identidade profissional. Assim, o professor passa a ser diariamente demandado a se inserir em um conjunto de práticas que lhe conferem subjetividades definidas a priori, enquanto sua autonomia e criatividade docentes são substituídas por um saber que ele passa a assumir na própria execução das políticas públicas, a partir de diferentes técnicas de si.

\section{Referências}

DELEUZE, G.; GUATTARI, F. Mil Platôs: Capitalismo e Esquizofrenia. vol. III. Rio de Janeiro: 34, 1996.

DELEUZE, G. Foucault. Trad. Claudia Sant'Anna Martins. São Paulo: Brasiliense, 2005.

FARIAS, I. M. Diferenças entre polivalência e politecnia: implicações para a formação sobre o trabalho no processo educativo. Educação Filosofia, Uberlândia, v. 13, n. 23, p. 11-19, jan./jun. 1998.

FOUCAULT, M. A tecnologia política dos indivíduos. In: FOUCAULT, M. Ética, sexualidade, política (Ditos \& Escritos V). Organização de Manuel Barros da Motta. Trad. Elisa Monteiro e Inês Autran Dourado Barbosa. 2. ed. Rio de Janeiro, Forense Universitária, 2006e [1988]. p. 301-318.

FOUCAULT, M. Foucault. In: FOUCAULT, M. Ética, sexualidade, política (Ditos \& Escritos V). Organização de Manuel Barros da Motta. Trad. Elisa Monteiro e Inês Autran Dourado Barbosa. 2. ed. Rio de Janeiro: Forense Universitária, 2006d. p. 344 -239.

FOUCAULT, M. Uma estética da existência. In: FOUCAULT, M. Ética, sexualidade, política (Ditos \& Escritos V). Organização de Manuel Barros da Motta. Trad. Elisa Monteiro e Inês Autran Dourado Barbosa. 2. ed. Rio de Janeiro: Forense Universitária, 2006c [1984]. p. 288-293.

FOUCAULT, M. A ética do cuidado de si como prática da liberdade. In: FOUCAULT, M. Ética, sexualidade, política (Ditos \& Escritos V). Organização de Manuel Barros da Motta. 
Trad. Elisa Monteiro e Inês Autran Dourado Barbosa. 2. ed. Rio de Janeiro: Forense Universitária, 2006b [1984]. p. 264-287.

FOUCAULT, M. A escrita de si. In: FOUCAULT, M. Ética, sexualidade, política (Ditos \& Escritos V). Organização de Manuel Barros da Motta. Trad. Elisa Monteiro e Inês Autran Dourado Barbosa. 2. ed. Rio de Janeiro: Forense Universitária, 2006a [1983]. p. 144-162.

FOUCAULT, M. As palavras e as coisas. Trad. Salma Tannus Muchail. 8. ed. São Paulo: Martins Fontes, 2000 [1966].

FOUCAULT, M. Nascimento da biopolítica. Curso dado no Collège de France. Trad. Eduardo Brandão. São Paulo: Martins Fontes, 2008 [1979].

FOUCAULT, M. Microfísica do poder. Rio de Janeiro: Edições Graal, 2010 [1981].

FOUCAULT, M. O sujeito e o poder. In: DREYFUS, H; RABINOW, P. Michel Foucault, uma trajetória filosófica: para além do estruturalismo e da hermenêutica. Rio de Janeiro: Forense Universitária, 1995. p. 231-249.

GOMES, G. S. Práticas discursivas de subjetivação do professor: técnicas de biopolíticas, 2019. 112 f. Dissertação (Mestrado em Letras) - Programa de Pós-Graduação em Letras, Universidade Federal do Sul e Sudeste do Pará, Marabá, 2019.

LARROSA, J. Tecnologias do eu e educação. In: SILVA, T. T. (Org.). O sujeito da educação. Petrópolis: Vozes, 1994. p. 35-86.

RUSSI, P. Legem Habemus: dispositivo de confissão. In: SOUZA. K. M. de (Org.). Dispositivos de poder/saber em Foucault: biopolítica, corpo e subjetividade. São Paulo: Intermeios; Goiânia:UFG, 2015. p. 31-42.

\section{Sobre as autoras}

Edileide Patrícia Câmara Lima (Orcid iD: https://orcid.org/0000-0003-0576-3923)

Mestra em Letras pela Universidade Federal do Sul e Sudeste do Pará (UNIFESSPA); graduada em Letras pela Universidade Federal do Pará (UFPA). É professora da Secretaria Municipal de Educação de Marabá (SEMED Marabá-PA).

Nilsa Brito Ribeiro (Orcid iD: https://orcid.org/0000-0001-9213-1726)

Doutora e mestra em Linguística pela Universidade Estadual de Campinas (UNICAMP); graduada em Letras pela Universidade Federal do Pará (UFPA). É professora do Instituto de Linguística, Letras e Artes, do Programa de Pós-Graduação em Letras e do Programa de PósGraduação em Dinâmicas Territoriais e Sociedade na Amazônia da Universidade Federal do Sul e Sudeste do Pará (UNIFESSPA).

Recebido em agosto de 2020.

Aprovado em outubro de 2020. 